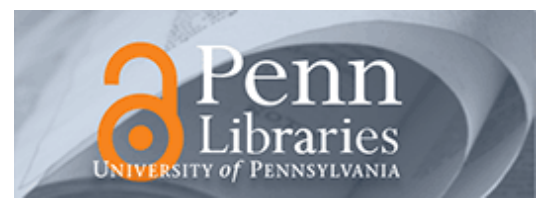

University of Pennsylvania

ScholarlyCommons

Marketing Papers

Wharton Faculty Research

6-2017

\title{
Does Adding Inventory Increase Sales? Evidence of a Scarcity Effect in U.S. Automobile Dealerships
}

Gerard P. Cachon

University of Pennsylvania

Santiago Gallino

Marcelo Olivares

Follow this and additional works at: https://repository.upenn.edu/marketing_papers

Part of the Business Administration, Management, and Operations Commons, Business Intelligence Commons, Management Sciences and Quantitative Methods Commons, Marketing Commons, Operations and Supply Chain Management Commons, and the Sales and Merchandising Commons

\section{Recommended Citation}

Cachon, G. P., Gallino, S., \& Olivares, M. (2017). Does Adding Inventory Increase Sales? Evidence of a Scarcity Effect in U.S. Automobile Dealerships. http://dx.doi.org/10.2139/ssrn.2286800

This is an unpublished manuscript.

This paper is posted at ScholarlyCommons. https://repository.upenn.edu/marketing_papers/340

For more information, please contact repository@pobox.upenn.edu. 


\title{
Does Adding Inventory Increase Sales? Evidence of a Scarcity Effect in U.S. Automobile Dealerships
}

\begin{abstract}
What is the relationship between inventory and sales? Clearly, inventory could increase sales: expanding inventory creates more choice (options, colors, etc.) and might signal a popular/desirable product. Or, inventory might encourage a consumer to continue her search (e.g., on the theory that she can return if nothing better is found), thereby decreasing sales (a scarcity effect). We seek to identify these effects in U.S. automobile sales. Our primary research challenge is the endogenous relationship between inventory and sales - e.g., dealers influence their inventory in anticipation of demand. Hence, our estimation strategy relies on weather shocks at upstream production facilities to create exogenous variation in downstream dealership inventory. We find that the impact of adding a vehicle of a particular model to a dealer's lot depends on which cars the dealer already has. If the added vehicle expands the available set of sub-models (e.g., adding a four-door among a set that is exclusively two-door), then sales increase. But if the added vehicle is of the same sub-model as an existing vehicle, then sales actually decrease. Hence, expanding variety across sub-models should be the first priority when adding inventory-adding inventory within a sub-model is actually detrimental. In fact, given how vehicles were allocated to dealerships in practice, we find that adding inventory actually lowered sales. However, our data indicate that there could be a substantial benefit from the implementation of a "maximizes variety, minimize duplication" allocation strategy: sales increase by 4.4 percent without changing the number of vehicles at each dealership, and a 5.2 percent is possible if inventory is allowed to decrease by 2.8 percent (and no more than 10 percent at any one dealer).
\end{abstract}

\section{Keywords}

supply chain management, applied econometrics, retail operations, inventory competition, empirical OM, instrumental variables, automobile industry

\section{Disciplines}

Business | Business Administration, Management, and Operations | Business Intelligence | Management Sciences and Quantitative Methods | Marketing | Operations and Supply Chain Management | Sales and Merchandising

\section{Comments}

This is an unpublished manuscript. 


\title{
Does Adding Inventory Increase Sales? Evidence of a Scarcity Effect in U.S. Automobile Dealerships
}

\author{
Gerard P. Cachon \\ The Wharton School, University of Pennsylvania, Philadelphia, PA 19104, cachon@wharton.upenn.edu \\ Santiago Gallino \\ Tuck School of Business, Dartmouth College, Hanover, NH 03755, santiago.gallino@tuck.dartmouth.edu \\ Marcelo Olivares \\ Industrial Engineering, Universidad de Chile, molivares@u.uchile.cl
}

\begin{abstract}
What is the relationship between inventory and sales? Clearly, inventory could increase sales: expanding inventory creates more choice (options, colors, etc.) and might signal a popular/desirable product. Or, inventory might encourage a consumer to continue her search (e.g., on the theory that she can return if nothing better is found), thereby decreasing sales (a scarcity effect). We seek to identify these effects in U.S. automobile sales. Our primary research challenge is the endogenous relationship between inventory and sales - e.g., dealers influence their inventory in anticipation of demand. Hence, our estimation strategy relies on weather shocks at upstream production facilities to create exogenous variation in downstream dealership inventory. We find that the impact of adding a vehicle of a particular model to a dealer's lot depends on which cars the dealer already has. If the added vehicle expands the available set of sub-models (e.g., adding a four-door among a set that is exclusively two-door), then sales increase. But if the added vehicle is of the same sub-model as an existing vehicle, then sales actually decrease. Hence, expanding variety across sub-models should be the first priority when adding inventory-adding inventory within a sub-model is actually detrimental. In fact, given how vehicles were allocated to dealerships in practice, we find that adding inventory actually lowered sales. However, our data indicate that there could be a substantial benefit from the implementation of a "maximizes variety, minimize duplication" allocation strategy: sales increase by 4.4 percent without changing the number of vehicles at each dealership, and a 5.2 percent is possible if inventory is allowed to decrease by 2.8 percent (and no more than 10 percent at any one dealer).
\end{abstract}

Key words: Retail Operations; Inventory Competition; Empirical OM; Instrumental Variables; Automobile Industry

History: June 1, 2017.

\section{Introduction}

In early 2008, before the financial crisis, car dealerships in the United States (U.S.) held enough vehicles to cover sales for 75 days (WardsAuto market data). However, immediately following the 
financial crisis automakers began drastic reductions in their inventories. By January 2010, days-ofsupply for the industry had dropped to less than 49, leading many dealers to complain that their low inventories were negatively affecting sales (AutomotiveNews (2010)). Were those complaints justified?

Adding inventory can increase sales for several reasons. For example, additional inventory reduces the chance of running out of stock (which constrains sales) and allows a dealer to expand the variety of options (e.g., trim, colors, options) to a customer. This increases the odds a customer finds a vehicle that sufficiently matches her preferences, thereby increasing the likelihood of a sale. Inventory can also change preferences. For example, seeing many cars on a dealers lot might cause a customer to infer that the car is popular (a dealer carries many cars only if the model is popular), thereby making the car more desirable to the customer.

There are also downsides to ample inventory. For instance, if there are many cars on a dealer's lot, then a customer might infer that the car is not popular, and it must not be popular for a reason, so the customer becomes less likely to purchase. Or, seeing that many units are available, a customer may become more likely to continue her shopping/search process at other dealers because she believes that if she decides to return to the dealership, the car she desires will still be available. Once the customer leaves, she might not return (because there is a chance she will find a better alternative elsewhere or she might change her mind to even purchase a vehicle), so this more active search lowers the dealership's sales.

In general, for simplicity, we use the label "variety effect" for any mechanism that assigns a positive relationship between inventory and demand, with the understanding that some mechanisms may not be directly related to product variety (as in when multiple units of the same product signals popularity/desirability). And we use "scarcity effect" for any mechanism with a negative relationship. Our objective is to empirically evaluate the strength of these effects in the U.S. auto industry and then to use those estimates to recommend how existing vehicles should be allocated across dealerships to maximize sales.

While it is possible to identify several mechanisms that connect inventory to sales, estimating the relationship between inventory and sales is complex primarily because it is reasonable to believe that inventory is chosen endogenously. For example, a simple plot reveals a positive relationship between the amount of inventory a dealer carries and the dealer's average weekly sales. But dealers that operate in larger markets are expected to carry more inventory and have higher sales even if inventory has no influence on demand merely because a firm rationally needs to carry more inventory when it serves more demand. To overcome this selection effect, we estimate the influence of inventory using only observed variation within dealer-model pairs rather than variation across 
dealerships and models. This approach is valid given the assumption that a dealer's market conditions are reasonably constant in our six-month study period (e.g., there is little change in local factors like demographics, population, or the degree of competition the dealer faces). However, even within a dealer-model pair, there is a concern that a dealer may change her inventory level in anticipation of changes in demand. For example, the dealer may build inventory due to a planned promotion. In that situation it is incorrect to conclude that the larger inventory caused the higher sales. To overcome this issue, we exploit shocks to dealers' inventories due to extreme weather events at upstream production locations. Extreme weather may disrupt production via a number of possible mechanisms (e.g., delays in inbound or outbound shipments, worker absenteeism, or adjustments in production schedules in anticipation of weather or in response to weather, etc.) and also is independent of dealer demand (as production generally occurs at a considerable distance from the dealership), thereby providing a valid instrument that allows us to estimate the causal impact of inventory on sales.

\section{How Inventory Impacts Sales}

In this section we describe several mechanisms by which more inventory can increase sales and then we discuss mechanisms that predict the opposite.

At a basic level, it is intuitive that more inventory can help to avoid running out of stock (i.e., being out of stock), thereby increasing sales. For example, if $q$ units of inventory are available of a single item and its stochastic demand is $d$, then expected sales of that item, $E[\min (q, d)]$, is increasing in $q$. Related to this "stockout effect", increasing inventory can increase the variety of available products, thereby increasing the choice available to customers. Expanding the set of available choices increase sales because customers are more likely to find an item that suits their preferences (see, e.g., Train (2009), Talluri and van Ryzin (2004), Smith and Achabal (1998)). Kalyanam et al. (2007) provide empirical evidence for this in a non-fashion apparel category. However, they are unable with their data to directly measure the relationship between inventory and sales.

Inventory can influence a consumer's engagement in the purchasing process. For example, if a consumer is not aware of an item, the consumer cannot even consider purchasing it - a large inventory may act like a billboard and increase awareness, which increases sales. Or, a consumer may infer that a large inventory implies a low price (e.g., the item must be on promotion or the dealer will be willing to negotiate a good deal), thereby motivating the consumer to include the item in her consideration set (see Zettelmeyer et al. (2006) for a study on the effect of dealership inventory on prices). If search is costly, then consumers are more likely to visit (and therefore buy from) a dealer that has a reputation for higher inventory-nobody likes to go to a store only 
to discover that the desired item is unavailable (e.g., Deneckere and Peck (1995), Dana Jr. and Petruzzi (2001), Bernstein and Federgruen (2004), Su and Zhang (2009), Matsa (2011)).

It is also possible that inventory changes preferences. For example, a consumer might infer from a large inventory that the item has good quality (why else would the dealer have so many), thereby making the item more desirable to the consumer - a good quality item has useful features and durability. For example, Balakrishnan et al. (2004) assume that inventory increases demand and study how this effect influences single-product inventory decisions in a deterministic environment.

In contrast to the various mechanism through which inventory potentially increases sales, there are several mechanisms that lead to a scarcity effect in which more inventory actually lowers sales. This could happen if consumers infer that an item with ample inventory is unpopular or low quality - there must be many units because nobody is buying the item (e.g., Balachander et al. (2009),Stock and Balachander (2005)). Or, a consumer might prefer an item that is perceived to be exclusive or rare, as in a collectible (e.g. Brock (1968); Brehm and Brehm (1981); Worchel et al. (1975); Tereyağoğlu and Veeraraghavan (2012)). This may apply to some specialty vehicles in the auto industry, but probably not to the sample of mainstream vehicles we consider.

If it is costly for consumers to consider all possible options, then low inventory may imply a low variety of options and higher confidence that a good option has been identified (e.g. Kuksov and Villas-Boas (2010)). Similarly, high inventory and high variety may create confusion or frustration (too many options to know where to begin), thereby leading to lower demand and sales (e.g. Iyengar and Lepper (2000), Schwartz (2004), Gourville and Soman (2005)).

A large inventory may indicate that a product will be available later on at a good price (because the dealer may need to discount the item), thereby encouraging consumers to wait before buying, which lowers current sales (e.g., Aviv and Pazgal (2008), Su and Zhang (2008), Cachon and Swinney (2009)). In contrast, with a low current inventory consumers not only anticipate that the price will not fall, they also anticipate that the item may not be available in the future. This can lead to a "buying frenzy" in which the low current inventory creates a sense of urgency among consumers to buy immediately (DeGraba (1995), Qian and van Ryzin (2008)). Soysal and Krishnamurthi (2012) use data from a specialty apparel retailer to document empirically that consumers do wait strategically for end-of-season discounts. Nevertheless, they find via a counterfactual analysis that reducing inventory reduces sales (through a stockout effect) even if profits may increase (because more items are sold at the full price).

Inventory may influence consumer search. Say a consumer finds a vehicle that she likes at a dealership. If the dealer has only one of that type of car, she may be inclined to stop her search and just buy the car-if she continues her shopping at other dealers, then she risks not finding a better car and losing the current car to another customer. But if the dealer has several of her 
desired cars, she may be more inclined to continue her search, and that search may lead her to make a purchase from some other dealership (See Cachon et al. (2008) for a model in which variety influences the degree of consumer search.). Alternatively, ample inventory may encourage her to delay making a purchase commitment so that she might further mull over the decision, or even cause her to forgo the purchase entirely.

To summarize, there are several mechanisms that suggest more inventory increases sales (ample inventory enables a better preference match, increases awareness, signals popularity, indicates availability and suggests the potential to obtain a good price). For simplicity, we collectively refer to these as variety effects given that variety is likely to be a key factor in consumer purchasing decisions in the auto industry. In contrast, other mechanisms suggest more inventory decreases sales (ample inventory reduces the urgency to purchase immediately while encouraging additional search, signals an unpopular vehicle, creates overwhelming choice, and suggests that prices will soon be lowered). We refer to these as scarcity effects. We seek to measure these effects in the auto industry using fine-grained field data. We find that how inventory is added to a dealer matters considerably - does the additional inventory expand the available set of sub-models or increase the number of units available within a sub-model. This knowledge allows us to devise a new method for allocating existing vehicles that yields higher sales without changing which vehicles are produced.

\section{Data Description and Definition of Variables}

As a general reference, during the period of our study six car companies accounted for about 90 percent of sales in the U.S. auto market. The company we focus on, General Motors (GM), captured 25 percent of the market. This market share was distributed across several different brands: Chevrolet, GMC, Pontiac, Buick, Saturn, Cadillac and Hummer.

The data used in our analysis can be separated into two groups. The first group includes the inventory and sales information for the dealers in our sample. The second group includes geographic location, weather information for all the GM dealers in our sample and all GM plants located in the U.S. and Canada.

\subsection{Dealer's Sales and Inventory Data.}

We obtained, via a web crawler, daily inventory and sales data from a website offered by GM that enables customers to search new vehicles inventory at local dealerships. The data collection was done from August 15, 2006 to February 15, 2007, and includes a total of 1,289 dealers in the following states: California, Colorado, Florida, Maine, Nebraska, Texas and Wisconsin. These states are geographically dispersed and somewhat geographically isolated - they may border with Mexico or Canada or have a substantial coastline. The dealers in the sample are all the GM dealers 
in those states and they represent approximately 10 percent of all GM dealers in the U.S. for the period under analysis.

The crawler collected specific information for each vehicle at a dealer's lot, such as its trim level, options, list price and Vehicle Identification Number (VIN). Our sample of GM vehicles includes all cars and a large portion of light-truck models manufactured and sold in the U.S. and Canada. VINs uniquely identify all vehicles in the U.S. Thus, they provide three key pieces of information. First, the VINs allow us to identify when a new car arrived at a dealer and when a sale happened (a vehicle is removed from a dealer's inventory). Second, the VIN code identifies the particular plant where the vehicle was produced even if the model is manufactured at multiple plants. Finally, the VINs provide us with information regarding dealer transfers - we can observe when a vehicle is removed from one dealer's inventory and added to another dealer's inventory within the state. If a vehicle leaves a dealer in week $t$ and does not reappear in another dealer's inventory in week $t+1$, then we code this as a sale. Otherwise, it is coded as a transfer. For example, car A is transferred from dealer 1 to dealer 2 and then sold at dealer 2, a sale is counted only at dealer 2 . We can only observe transfers between dealerships within the same state. We anticipate that we observe the majority of transfers because transfers occur in a limited geographic area. ${ }^{1}$ We removed from our sample a limited number of dealerships that opened or closed during the period under analysis.

Figure 1 shows the geographic location of GM plants and dealers, and Table 1 summarize the number of dealers in each state in our sample.

\subsection{Geographic Location and Weather Data}

For each dealer and all 22 GM plants supplying vehicles in our sample (located in the U.S. and Canada), we obtained their address and exact geographic location (longitude and latitude) from GM's website.

Our first source of weather data comes from the National Weather Service Forecast Office (NWSFO). We obtained daily weather information for every dealership and plant location in our sample for the period August 15, 2006 to February 15, 2007. Included in the sample are for each day the day's maximum, mean and minimum values for the following weather variables: temperature, wind speed, humidity, pressure, visibility and dew point. We also obtained information on the type of event during a day (rain, thunderstorm, snow, etc.). We identified the closest weather station to each plant and each dealer. The selected weather stations are close to our plants with a mean and median distance of 12 and 10 miles, respectively. No plant is further than 32 miles from its corresponding weather station. To assess whether a station's weather is likely to be similar to the

\footnotetext{
${ }^{1}$ We also conducted the analysis restricting the sample by dropping dealers with more than $75 \%$ unobserved neighbor dealers and the results were similar
} 
weather at its nearby plant, we constructed a sample of weather stations that are between 30 and 60 miles apart. In this sample, the correlation in our weather variables is no less than 95 percent, suggesting that the weather reported at the nearby weather station is representative of the weather at the plant ${ }^{2}$.

The Second source of data comes from the National Climatic Data Center from NOAA. On their website they share access to the "Storm Events Database" (NOAA (2015)). The type of storms and events recorded on this database are consistent with the Storm Data listed in Table 2 of Section 9 of NWS Directive 10-1605 (NOAA (2016)). The storm data is reported at the FIPS level. The county FIPS number is a unique number assigned to the county by the National Institute for Standards and Technology (NIST) or NWS Forecast Zone Number. We matched production plants to county and ZIP codes to establish a one-to-one link between the Storm Event Database and the production plants.

\section{Model Specification}

We seek to estimate the impact of inventory and variety on sales. The available data was used to construct a panel data-set where the unit of analysis is the log of sales plus one of a particular vehicle model $i$ at a specific dealership $j$ during a week $t\left(\right.$ Sale $\left._{i j t}\right)$. Expected sales during a week are influenced by the total number of vehicles available at the dealership during the week (Inventory $y_{i j t}$ ), the number of varieties of the model that where available (Variety V $_{i j t}$, to be described in more detail shortly), plus other factors that could influence the demand for vehicles at the dealership. Figure 2 illustrates the relationship between the key variables in our analysis - sales, inventory and variety.

Figure 2 shows multiple effects between the three key variables. First, there is a direct effect of inventory on sales. An example of this effect is when a low level of inventory signals low future availability of the vehicle model and leads to a "buying frenzy" behavior, or when a high level of inventory signals lower prices and therefore increases sales. Therefore, the sign of this relationship is ambiguous. Second, there is a direct effect of variety on sales, as when more variety leads to a better match of customer preferences, thereby increasing sales. Higher variety could also lead to more confusion in choosing among too many options, lowering sales. Hence, the sign of this relationship is also ambiguous. Third, there is an indirect effect of inventory on sales through variety: adding inventory can lead to an increase in variety, which in turn could affect sales.

Using the indexes $i$ for dealership, $j$ for model and $t$ for week, the following regression equation is used to estimate the impact of inventory and variety on sales:

\footnotetext{
2 The locations consider for this analysis were: Marysville, Ohio and Columbus, Ohio; Washington DC and Baltimore, Maryland; Kansas City, Missouri, and Topeka, Kansas; Lansing, Michigan and Grand Rapids, Michigan
} 


$$
\text { Sales }_{i j t}=\beta_{0}+\beta_{V} \text { Variety }_{i j t}+\beta_{I} \text { Inventory }_{i j t}+\text { Controls }+\varepsilon_{i j t}
$$

The error term $\varepsilon$ represents factors that affect sales which are unobservable in the data. Dealerships and manufacturers may predict some of these factors in advanced and use them in their demand forecast to choose inventory levels and model variety requirements (see Figure 2 for an illustration). Hence, $\varepsilon$ is likely to be positively correlated with Inventory and Variety making these variables endogenous in the equation (1).

To obtain unbiased coefficients for $\beta_{V}$ and $\beta_{I}$ we need to find a set of variables that can be excluded from the sales equation (i.e. do not affect sales directly) but have a direct impact on inventory and variety.

If weather at the plant affects its production, then weather shocks at the plant affect the inventory level at the dealerships. Because most of the plants are located far away from the dealerships in our study, weather shocks at the plants should be unrelated to the local demand for autos. Weather shocks at the plants, defined by the vector of covariates $W$, are excluded from equation (1) while affecting inventory levels at the dealer and therefore are valid instrumental variables for Inventory.

Although dealerships can control the number of vehicles of a particular model that they receive, they typically have little control on the exact sub-models that are allocated to them. The variations in variety after controlling for inventory levels should be for the most part unrelated with the demand forecasts or other unobservable factors related to demand. By explicitly controlling for the inventory level we are able to identify separately the effect of variety. However, we cannot completely rule out the possibility that Variety is also endogenous in equation (1). Hence, Variety has to be instrumented to be certain that consistent estimates are obtained for the coefficients in equation (1).

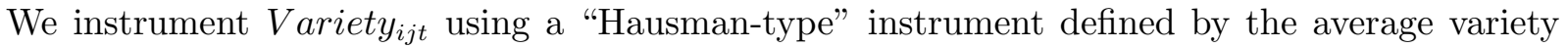
for model $j$ at the three closest dealers $(h)$ to dealer $i$ that are at least 150 miles away from dealer $i$, which we labeled NearVariety ${ }_{h j t}$. Distant dealers are selected to avoid any potential correlation between their variety and the sales at dealer $i$. However, we can verify that the variety for a particular model $j$ within a region is correlated across dealers because dealers within a region tend to receive vehicles from a common production mix through the same distribution channels. Hence, variety at the other dealers in the region, but outside a dealer's market, are excluded from equation (1) while affecting variety levels at the dealer. Consequently, the explanatory variable NearVariety $y_{h t}$ is a valid instrumental variable for Variety $_{i j t}$ in equation (1).

Given the valid instruments for the two endogenous variables (Inventory and Variety) we are able to obtain unbiased coefficients for $\beta_{I}$ and $\beta_{V}$ by implementing a two-stage least squares (2SLS) 
estimation approach. Although so far we emphasize the use of instrumental variables to address the endogeneity bias that exists between inventory, variety and sales, the instrumental variable approach also allow us to address any concern arising from other potential omitted variables in the model.

Controls. Equation (1) includes several control variables. Model-dealership fixed-effects are included to control for invariant characteristics of each dealer and model: dealer location, the average popularity of a model at a particular dealership, the intensity of competition a model faces at each dealer, the MSRP of a model, the average discount policy a dealer offers for a particular model, among other characteristics. Seasonal controls include dummy variable to account for changes in the sales across weeks. This is implemented by grouping dealers into four geographic regions: $\{$ Florida, Texas\}, \{Colorado, Nebraska\}, $\{$ Maine, Wisconsin $\}$, and $\{$ California $\}$. Let $r(i)$ be the region containing dealership $i$. We include the set of dummy variables Seasonal $_{r(i) t}$ to control for different seasonal patterns across geographic regions, e.g., a different weekly sales pattern in Texas than in Wisconsin. In addition, the regression includes covariates capturing local weather at each dealership to control for the effect of local weather on sales and demand forecasts. Steele (1951) and Murray et al. (2010) present examples of how local weather affects retail sales and Busse et al. (2014) show evidence of this effect specifically for car dealers. This control is particularly important to ensure that plant weather is an exogenous instrumental variable, because for some dealerships local weather could be correlated with plant weather.

Measuring variety. To identify which of the main effects of inventory on sales described earlier dominates, we identify separately the impact of our two measures of availability-inventory and variety. For example, a negative effect of Variety $_{i j t}$ would suggest that the confusion effect dominates the impact on sales. Although Inventory $y_{i j t}$ can be objectively defined as the number of vehicles available for a model, variety could be defined in different ways depending on the relevant product characteristics that are considered by customers when making their purchase decision. For example, a customer wanting to buy a Chevrolet Malibu may consider two vehicles with different horsepower as two different products, but could be indifferent on the color of the car. To measure Variety, it is necessary to define a set of attributes that describes relevant differences across vehicle options within a model. See Hoch et al. (1999) for a framework on how customers perceive variety.

The VIN of a vehicle contains information about vehicle characteristics, including the model, body style, engine type and restraint type. We use all these relevant characteristics reported in the VIN to define the different possible variants of a model and we refer to each variant as a sub-model. The variable AvailVar ${ }_{i j t}$ is the number of sub-models of a model $j$ available at dealership $i$ during 
week $t$. The assumption being that the variety information included in the VIN describes relevant differences across vehicle options from the customer perspective.

Table 3 summarizes the number of different sub-models observed in our data and the average Variety $_{i j t}$ observed at the dealerships for a sample of models. The table reveals that there is variation in the number of sub-models available across the set of models. Hence, it is plausible that the impact of variety is different across models: for example, adding one more sub-model of a Cobalt (which has many sub-models) can have a smaller impact than adding one more sub-model of an Equinox (which has fewer available sub-models). To account for this, the amount of available variety can be measured relative to the number of sub-models that exist for that model. Denote MarketVar ${ }_{j}$ as the total number of sub-models that were observed for model $j$. Our measure of variety is defined as:

$$
\text { Variety }_{i j t}=\frac{\text { AvailVar }_{i j t}}{\text { MarketVar }}
$$

Table 4 and Table 5 presents descriptive statistics and correlations respectively for our main variables.

Our period of analysis comprises the production period of model-year 2007 (most of the model changeovers occurred between June and August). However, there are some 2006 models observed in the inventory (less than 30\%) which are considered as different sub-models of the same model and will therefore add to variety. These vehicles remaining from model-year 2006 are typically discounted through rebates and dealer incentives. Hence, a positive correlation between Variety and Sales could be driven by seasonal discounts of the 2006 model-year vehicles. This issue is addressed in two ways. First, the control variables include week fixed effects, which would capture the seasonal discounts following the model changeover period. Second, Variety is instrumented with the variety of other dealerships. Hence, the effect of variety is identified using the variation of inventory across different regions, controlling for seasonal patterns that affect variety over time (such as price discounts in model changeover periods).

Weather Instrumental Variables. Our instrument can work in several ways: bad weather can affect the supply of parts to the production line slowing the production process; weather conditions can affect employee behavior both in their task performance and by increasing absenteeism; or weather can delay shipments of vehicles to dealers. Alternatively, production schedules could be altered in anticipation of weather.

To use weather as an instrument we considered the data obtained from NOAA on "Storm Events". The benefit of considering this variables resides in its simplicity and transparency since 
the decision of whether there is an extreme event or not is define by NOAA. This definition is location specific, NOAA uses different criteria to announce the extreme event at different locations (e.g. 2 inches of snow in North Carolina can be characterized as an extreme event whereas the same snowfall in Massachusetts would not). To implement the analysis we group the different events reported by NOAA into six variables according to the type of event: thunder storms, winter storm, tropical storm, heat wave, high wind, and flood. Each one of these six variables are an indicator of whether a particular production plant was affected by an extreme weather event during week $t$.

An alternative estimation approach of the overall effect of inventory. Assuming that inventory has a linear effect on variety as characterized by the $\gamma$ coefficient of Figure 2, it is possible to estimate the overall effect of inventory on sales - which corresponds to the direct effect $\beta_{I}$ plus the indirect effect through variety, $\beta_{V} \gamma$ (see Figure 2). In this case we are interested to estimate:

$$
\text { Sales }=\left(\beta_{I}+\beta_{V} \gamma\right) \text { Inventory }+\gamma_{S}^{\prime} Z+\varepsilon^{\prime},
$$

The error term $\varepsilon^{\prime}$ represents factors that affect sales which are unobservable in the data. Under the exogeneity assumption $E\left(\varepsilon^{\prime} \mid Z, W\right)$, the coefficient $\beta_{I}^{\prime} \equiv \beta_{I}+\beta_{V} \gamma$ can be estimated via instrumental variables, instrumenting Inventory with the weather variables $W$. This provides an alternative estimate of the overall effect inventory on sales. The drawback of this approach is that it doesn't identify separately the effect of inventory and variety on sales. In particular, this precludes analyzing the allocation strategies described in section 7 .

\section{Results}

To validate our instruments beyond the argument presented earlier we present the results obtained on the first stage of the 2SLS estimation for each one of the two endogenous variables. This set of results include the six extreme weather factors described before and the variety measure for the three closest dealers, outside the 150 miles exclusion area, from the focal dealer. Table 6 reports the estimation results for the first stage analysis. Column (1) shows the estimates for Inventory and Column (2) present the estimation when instrumenting Variety. In addition, to the relevant coefficients being significant in the first stage we implemented an F-Test of the instruments and verified that they are in a range that allow us to to consider them statistically valid: $211.07(p$ $=0.000)$ for the weather instrument in the Inventory estimation and $717.46(p=0.000)$ for the variety instruments in the Variety estimation. Both these test results are well above the reasonable expectation for an instrument to be statistically meaningful.

Table 7 reports the results of the 2SLS estimation with bootstrap robust standard errors ${ }^{3}$. Column (1) shows the estimates of equation (1), without instrumenting inventory or variety. Column

\footnotetext{
${ }^{3}$ The bootstrap was implemented at the dealer-model level. We select a random sample of dealer model combinations
} and include the complete panel for the selected pairs. We implemented 500 bootstraps for our main results. 
(2) shows the estimates of equation (1) after instrumenting the endogenous variables with the 2SLS approach. If the estimation does not account for potentially endogenous variables (Column 1 ), inventory seems to have a positive effect on sales and the same is true for variety. However, the 2SLS estimates suggest that the direct effect of inventory $\left(\beta_{I}\right.$ in Figure $\left.(2)\right)$ is negative and statistically significant, but the effect of variety $\left(\beta_{V}\right)$ is positive and also statistically significant. In other words, the 2SLS estimates indicate that sales increase if new sub-models are made available to customers, but sales decrease if inventory is added to a sub-model that is already available at the dealership.

Our estimates suggest that adding inventory without increasing variety has negative and statistically significant effect on sales. However, different vehicle allocation policies can give different results. Figure 3 illustrates the overall impact of inventory on sales with the vehicle allocation policy that maximizes the expansion of variety (black line) compared to the allocation policy that expands inventory without increasing the number of sub-models available (dashed line). As is apparent from the figure, whether adding inventory increases or decreases overall sales depends on how vehicles are allocated to dealerships. A more precise analysis of alternative vehicle allocation policies is described in Section 7.

As proposed earlier, the overall impact of inventory on sales can be obtained by estimating equation (3) directly. Column (4) in Table 7 shows these estimates when inventory is not instrumented and Column (5) shows the result when implementing the 2SLS approach for inventory alone. Once again we can observe how the instrument corrects the bias in the estimation when the endogeneity is ignored. The coefficient of inventory is -0.009 , which is close to our previous estimate based on the coefficients of column (2) (which gave -0.008). This provides support to validate the consistency of the estimates of column (1).

As mentioned in Section 4, if inventory is set in anticipation of demand, then $\varepsilon$ is likely to be positively correlated and therefore the OLS estimate of the inventory coefficient could be biased upward. Column (2) is consistent with this result: in fact, the bias is so severe that the coefficient on inventory changes sign and becomes negative with statistical significance. Column (3) in Table 7 shows the estimates of equation (1) after instrumenting only the endogenous inventory and assuming that variety is not endogenous. We can observe that ignoring the potential bias of variety results in a larger estimate for variety, the difference between the two coefficients is statistically significant, suggesting that it is important to instrument both inventory and variety to obtain reliable estimates.

To repeat, the estimates in Column (2) of Table 7 and the sensitivity analysis presented on Figure 3 suggest that (i) adding inventory decreases sales if variety is held constant (a scarcity effect), (ii) although increasing inventory can expand variety and variety has a positive impact on 
sales, the overall effect of increasing inventory is negative given the way vehicles are allocated in our sample, and (iii) adding inventory while simultaneously expanding variety can increase sales.

Mechanism. Several of the mechanism discussed earlier are consistent with these findings and several are not. For example, our findings are consistent with the notion that more variety improves the match between consumer preferences and the available inventory, thereby increasing the likelihood that a customer makes a purchase. In contrast, the results are not consistent with the notion that more variety creates confusion or higher evaluation costs, thereby reducing demand - in some categories it is possible that the confusion effect is real and sufficiently strong, but with automobiles it appears that consumers are more likely to buy when they have more options to choose from.

Our findings suggest that dealer pricing or consumer bargaining do not have a strong impact on the relationship between inventory and sales. As shown by Moreno and Terwiesch (2015) one would expect that a dealer is more likely to offer a better price when the dealer has an above average amount of inventory because the dealer would want inventory to return to a more normal level. We observe that sales decrease as inventory increases (holding variety constant) - if this is to be explained by pricing, then one needs to be willing to assume that dealers increase their prices when they have more inventory. Similarly, our estimates cannot simply be explained by a stockout effect - if adding inventory prevents stockouts, then coefficient $\beta_{I}$ should be positive, not negative.

Although our results indicate the presence of a scarcity effect, they are not consistent with all mechanisms that lead to a scarcity effect. For example, a scarcity effect can occur if consumers infer that ample inventory is a signal that a car is not popular, possibly due to poor design or quality. For this to explain our data, the inventory signal would have to be at the sub-model level rather than at the model level - a consumer would have to believe that ample inventory of two-door Malibus is a bad signal for two-door Malibus, but the overall number of Malibus is not a negative signal. While we cannot rule this out, it does not seem plausible. We suspect that a consumer would infer quality, popularity and design based on the total inventory of a model level rather than based on the inventory of each of the various sub-models. If that is the case, then inferences of popularity cannot explain the negative relationship between sales and inventory, controlling for variety.

The scarcity effect we observe is consistent with the notion that inventory influences consumer search. Consumers are likely to desire a particular sub-model. If there is only one unit available of their desired sub-model, then they may discontinue their search for a new vehicle and purchase the vehicle. However, if the dealer has several units that fit the consumer's preference, the consumer may continue her search (or delay the purchase commitment to give further time to reflect upon the decision), feeling confident that if she does not find a better match, she can return to the dealership. If the consumer continues her search, then at the very least it delays the sale, but worse, 
it risks losing the sale - the consumer might discover a better match at another dealership. Thus, we find evidence that low inventory reduces consumer procrastination and motivates an immediate sale.

\section{Robustness Analysis}

This section considers several robustness checks. In particular, we consider different seasonal controls, spurious effects, different specifications for the instruments, including additional plants located in Canada, competition among dealers and transfers between dealers.

\subsection{Seasonal Controls}

Our identification is driven by variation in the weather events at the plants were vehicles were assembled and shipped from to the dealerships. Our estimation strategy would be invalidated if there is an unobserved factor that affects the weather at the plant and the likelihood of moving inventory produced at those plants to the dealers. However, extreme weather events are a natural experiment: there are no factors related to demand or supply of vehicles that could possibly correlate with the occurrence of these low-probability events at a specific plant. In other words, demand for vehicles does not plausibly cause weather events. That said, we must rule out correlation between potential demand confounders that are likely to occur at the same time of the year as weather events. Consequently, we validate our results considering multiple specifications that control for different levels of seasonality and trends.

In all the following models we consider the same structure as in the main model (a regression of sales as a function of two endogenous variables, Inventory and Variety with the same instrumental variables) but we change the controls for trends and seasonality. We consider five additional specifications to the base model:

- Model A: Weekly dummies interacted with 4 different zones - our Base Model. (104 dummies Total)

- Model B: Individual weekly dummies and a dummy for each one of the zones (30 dummies Total)

- Model C: Weekly dummies interacted with 26 different vehicle models. (676 dummies Total)

- Model D: Individual weekly dummies and a dummy for each one of the modes. (52 dummies Total)

- Model E: Individual linear trend for each one of the 26 vehicle models. (26 separate trends by model)

- Model F: Weekly dummies and Individual model trend. (26 dummies Total and 26 separate trends) 
Table 8 presents the result of the second stage under each one of these models. The first column corresponds to our base model (the one presented in Column 2 of Table 7).

All six models present consistent results with respect to the magnitude and direction of our variables of interest. The results are robust to alternative specifications of seasonality, suggesting that the effect is not driven by unobservable seasonal effects, ruling out this as a potential confounder.

\subsection{Spurious Effects}

An additional concern is that, because the weather events studied are relatively infrequent, each event is influential in the sample and could potentially identify some spurious relationship. We implemented the following "placebo test" to rule out this explanation. We created 100 replications of our base model where we randomly generate the instruments for the analysis. The instruments were generated with the same frequency that appear in our data and we force the event to occur within the same week range where we observe the events. We then estimated the model for each of the 100 replications, each one with a different set of randomly-generated instruments. Out of the 100 runs, in only 7 instances are all instruments statistically significant at the $5 \%$ level and the joint test of significance for the first stage of the instruments is larger than with the real instruments. Overall, this analysis passes the placebo test, providing further confidence that our instruments are valid and the main findings are not a result of pure chance.

\subsection{Alternative Definition of Weather as an Instrument}

We considered an alternative measure of the weather impact at the plants by using actual weather factors, rather than taking the definition of storm events from NOAA. To do this we constructed a set of extreme weather measures from the different weather factors captured by the different weather stations. These weather variables are described in detail in Table 2. We included Wind, Fog, Rain and Snow variables because each of these weather events may influence travel to and from a plant. Cloud could proxy for other inclement weather and could influence employee behavior. High Temp is included because it could influence ambient temperature within the plant or employees that must work outside (e.g., loading docks). Low Temp may proxy for hazardous road conditions (e.g. ice). Some of the variables, such as Wind and Cloud, directly capture weather shocks. For other measures - specifically for Rain, High Temp, Low Temp and Snow-we estimated specifications including multiple levels of the variable to capture potential non-linear effects on production.

Some of these weather variables have a weak impact on dealership inventory, in part because of the high correlation between the many alternative measures of weather that we considered. Using a large number of instruments in a two-stage least square estimation can induce bias on the estimates (Buse (1992)). There is also a rich literature that discusses other challenges that can arise when dealing with multiple instruments, in particular when some of these instruments might be weak 
(Bekker (1994), Donald and Newey (2001), Chao and Swanson (2005)). Kloek and Mennes (1960) proposed a practical solution to solve the shortcomings of dealing with a large number of (possibly weak) instruments. The idea is to use a reduced number of principal components of the original set of instruments as the instrumental variables in the estimation. We follow a similar methodology in our approach.

We reduced the thirteen weather variables to five principal components capturing more than fifty percent of the variance on the original variables. Hence, the components obtained contain a good portion of the information in our instruments.

The first stage of the 2SLS estimation of equation (1) shows that when instrumenting Inventory the five principal components coefficients are significant for the five factors - the average $t$ value for each one of the factors is 12 and the $p<0.000$ in every case. Once again, to validate the overall strength of our instrument, we observe that both the R-squared (0.9) of this regression and the F-test $(184 ; p<0.000)$ of join significance of the instruments exceed the usual standards to rule out weak instruments. To instrument Variety we considered the same set of instruments included in our main results.

The results of the two 2SLS estimation with these set of instruments are included in Table 9. Column (1) show the results when instrumenting both inventory and variety, which is analogous to the one presented on Column (2) of Table 7. Column (2) of Table 9 show the results when only inventory is included in the analysis, like done for the analysis presented in Column (5) of Table 7.

These results are directionally consistent with our main model results presented in Table 7 and the magnitude of the estimated effect are also comparable. This gives us reassurance that the weather instruments capture an underlying mechanism and not picking up a spurious effect. If anything, the results with this new set of instruments show a larger effect to the one presented with our main model since in this case the effect of inventory is more negative while the impact of variety is larger (comparing Column 2 on Table 7 and Column 1 on Table 9). However, because the criteria for constructing this new set of instruments is more subjective, we present our finding of the previous section as our main findings (which rely on the definition of extreme weather events provided by NOAA).

\subsection{Additional Plants}

Constructing the weather instruments, as described in the previous section, allows us to include additional production plants in our analysis. GM has a number of plants in Canada that produce car models that are sold in the U.S. NOAA does not report extreme weather events, our preferred instrumental variable, for Canada. However, the Canadian weather stations offer the historical 
information for the same set of weather variables we considered to estimate the weather factors in the previous section. This allows us to expand our sample of both plants and dealer-models and further validate our estimation results.

We estimated a new set of five weather factors implementing a similar approach to the one described in the previous section. Using these factors we instrumented inventory and sales and included the additional models. The results of this analysis are presented in Table 9. Column (3) shows the results when both inventory and variety are included and Column (4) presents the results when we consider only the impact of inventory on sales. Again, these results are directionally consistent and of the same magnitude as our main model results presented in Table 7 (Columns 2 and 5). This indicates that our findings are robust to an expanded sample with additional plants and models.

\subsection{Competition Among Dealers}

The dealers in our sample face different levels of competition from GM and non-GM dealerships. As mentioned earlier, the dealer-model fixed effects included in our main specification account for the average competition intensity for a particular model at a dealer. However, the inventory level for a model could vary across dealers from one week to another and this variation may be known to the dealers. To explain our results, low inventory at dealer A in a market would need to be correlated with reduced competition from the other dealerships in the same market, thereby allowing dealer A to increase his sales. Although we do not view this as likely, to explore the impact of competition we estimate our main model with a subsample of dealers that do not face competition in their local market from other GM dealers. Based on empirical work defining the relevant market for a dealership (Albuquerque and Bronnenberg (2012)), we defined a sub-sample of dealers with no competing GM dealer (of any GM brand) within a 15 mile radius.

Table 10 reports the analysis with this sub-sample. Columns (1) and (3) correspond to the analysis ignoring the bias and Columns (2) and (4) correspond to the analysis when we implement the 2SLS with the extreme weather instruments. These results are consistent with the results obtained with the complete sample and suggest that our main results are not confounded by the impact of competition patterns between GM dealers.

\subsection{Transfers Between Dealers}

If a dealer lacks a sub-model that a consumer wants, the dealer can try to convince the consumer to purchase a different sub-model or the dealer can try to find the desired sub-model at a nearby dealer. If the desired vehicle is found at another dealer, a transfer can occur between the two dealerships if they can agree to the transfer. In many cases this transfer involves a swap of vehicles rather than an exchange of cash - the requesting dealer has a customer that will purchase the donating dealer's 
vehicle, and in return, the requesting dealer offers one of its vehicles to the donating dealer, who probably doesn't have an customer at the time of the swap willing to purchase the vehicle received. In our sample, 12.9 percent of total sales are for vehicles that were transferred from one dealership to another. We next discuss three issues raised by the presence of transfers.

The use of transfers could be consistent with a negative relationship between inventory and sales when a dealer has fewer vehicles, it compensates by making more frequent use of transfers. Through this mechanism, lower inventory doesn't induce higher sales because of influencing consumer search or preferences, but rather by influencing dealer behavior (i.e., they do more transfers). To test this alternative hypothesis we considered a model with the log of transfer sales as the dependent variable and inventory at the dealer as the independent variable, and the same set of controls included in $Z$. This regression of transfer sales does not find a significant relationship between inventory and transfer sales, which suggests our results are not well explained by the additional use of transfers when inventory is low.

We do not observe all transfers because while we know the location of all GM dealerships within the country, we could not monitor the inventory of dealerships in all states in the U.S. Hence, there are some unobserved transfers between dealers across states. To address this concern, we identify for each state a radius such that $90 \%$ of the transfers in our sample occur between dealerships within this radius. Across the entire sample, this radius is 200 miles (i.e., $90 \%$ of transfers in our sample occur between dealers that are within 200 miles of each other). As expected, the radius is higher for less dense states such as Nebraska and lower for states like California. Next, we restrict our sample to dealerships for which at least $75 \%$ of the dealership's neighbors within the state-specific radius are included in our set of monitored dealerships. For example, a dealership in northern Florida might be excluded because only $60 \%$ of the dealerships within 196 miles (the radius for Florida) are within Florida. This excludes dealerships that are more likely to have unobserved transfers (because they are close to state borders) and retains dealerships for which we are likely to observe nearly all of their actual transfers. The results with the restricted sample do not change in sign or magnitude, suggesting that unobserved transfers do not affect our results.

Finally, the use of transfers is relevant for the validity of the variety instrument, which requires that variety of distant dealers is correlated with a focal dealer's variety but not the focal dealer's sales through unobserved variables. This would be a concern if a focal dealer used the availability of distant vehicles to increase its sales. The fact that inventory is uncorrelated with the use of transfer is encouraging that this is not the case. In addition, dealers generally attempt to sell what is on their lot, suggesting that they do not encourage customers to select from distant inventory. But for further confidence, we replicated the main model using a variety instrument based on a 200 mile exclusion instead of the main model's 150 mile radius. Only $10 \%$ of transfers come from 
dealers that are 200 miles or greater away, and only $1.8 \%$ of those are from dealers used in the variety instrument. Hence, the vehicles used for our variety instrument represent only $0.166 \%$ of all vehicles in our sample. Table 11 reports the results using this more restrictive sample for the variety instrument are essentially unchanged. This gives us confidence that our variety instrument is valid even in the presence of transfers.

\section{The Impact of Inventory Allocation}

Our empirical estimation reveals that adding inventory to a dealer is only beneficial if the added vehicle expands the dealer's set of sub-models - increasing the inventory of a particular sub-model actually lowers sales. This section explores the potential sales benefit of using this result to better allocate vehicles to dealers. We take two different approaches. The first approach estimates the potential sales improvement from reallocating the existing vehicles among the dealers in a small

local area. The second approach considers only the incoming vehicles to a larger region (e.g., a state) and attempts to maximize sales by allocating those vehicles to the dealers in the area while leaving the dealers' existing inventory intact.

Given the size of our data-set (1289 dealers, 30 weeks, etc) we focus our analysis on a particular week (the week with the median number of total cars) and the ten most popular models. These models - Cobalt, Equinox, G6, HHR, Impala, Suburban, Tahoe, TrailBlazer, Saturn, VUE, and Yukon-represent approximately sixty percent of the sales across all the GM models in our sample. We emphasize that this analysis is only suggestive of the potential benefit of changing their allocation process. Due to computational effort, we are unable to analyze all reasonable parameters estimates, all models, and all weeks in our sample.

\subsection{Local Reallocation Among Dealers}

The analysis in this section partitions dealers into small local markets. Dealership inventory can be observed in detail at the sub-model level: some dealers may have multiple units within a sub-model and other dealers within the same local market might not have any vehicles of that sub-model. Hence, based on our results, both dealers could benefit from a vehicle transfer - moving a vehicle from the dealer with multiple units to the dealer with no units increases sales at both dealers. Thus, we evaluate for each model the total sales gain across all markets that could be achieved by efficient vehicle transfers so as to maximize the variety each dealer offers and to minimize the duplication of units within sub-models. We do not model the cost of actually transferring these vehicles - any sales improvement from reallocation would have to be compared with the cost of achieving the better balance of variety across dealers. 
We group dealers as part of the same local market if they are in the same core based statistical area (CBSA). ${ }^{4}$ We consider vehicle swaps only between dealers in the same CBSA, and so that the total inventory within each CBSA remains constant. In addition, we impose a cap on the amount of inventory a dealership can reduce of a given model.

The decision variable is the number of vehicles of sub-model $k$ of model $j$ allocated to dealership $i$, $Q_{i j k}$, in a selected week. For each CBSA and each model $j$ we solve the following integer non-linear optimization problem:

$$
\max _{Q_{i j k}}\left[\sum_{i=1}^{n} \exp \left(\hat{\delta}_{i j}+\hat{\beta}_{I} \sum_{k=1}^{m_{j}} Q_{i j k}+\hat{\beta}_{V} \cdot \operatorname{Variety}_{i j}\right)\right]
$$

s.t.

$$
\begin{gathered}
\sum_{i=1}^{n} Q_{i j k}=\sum_{i=1}^{n} I_{i j k} \quad \forall j, k \\
\sum_{k=1}^{m_{j}} Q_{i j k}=(1-\lambda) \sum_{k=1}^{m_{j}} I_{i j k} \quad \forall i, j \\
\operatorname{Variety}_{i j}=\frac{\sum_{k=1}^{m_{j}} \mathbb{I}\left(Q_{i j k} \geq 1\right)}{m_{j}} \\
0 \leq Q_{i j k} \leq T_{i j k}
\end{gathered}
$$

where

- $n$ is the number of dealers within a CBSA

- $m_{j}$ be the total number of sub-models for model $j$.

- $I_{i j k}$ is dealer $i$ 's initial endowment of inventory of sub-model $j k$ (i.e., if there is no reallocation).

- $\hat{\beta}_{V}$, and $\hat{\beta}_{I}$ are the estimated coefficients from the first column of Table 7 .

- $\hat{\delta}_{i j}$ is the estimated fixed effect for dealer $i$ and model $j$

- $T_{i j k}$ is the maximum number of vehicles that dealer $i$ carried for sub-model $j k$

Constraint (5) ensures that the reallocation does not change the total inventory within the CBSA of model $j$. Constraint (6) ensure that dealer $i^{\prime} s$ inventory of model $j$ cannot decrease more than a $\lambda$ fraction of the initial inventory. When $\lambda=0$, these constraints imply that each dealer that gains a vehicle must also give up a vehicle of the same model. Constraint (8) ensures that at the end of the swaps the maximum number of units of a particular sub model $k$ at dealer $i$ will be less or equal to the maximum number of units of any sub model $k$ that dealer $i$ was carrying at the beginning of

\footnotetext{
${ }^{4}$ CBSA is a U.S. geographic area defined as an urban center of at least 10,000 people and adjacent areas that are socioeconomically tied to the urban center by commuting.
} 
the swaps. The objective is then to maximize Variety $_{i j}$ while keeping each dealership's inventory constant.

The first column on Table 12 shows the solution to this math program when imposing the constraint that inventory of all model-dealers to remain constant $(\lambda=0)$, as measured by the average potential sales improvement. We find that on average, exchanging inventory among dealers within a CBSA with the objective of maximizing each dealer's offered variety yields a weighted average sales gain of 4.4 percent.

The second and third columns of the table allow up to a $10 \%$ reduction of a model's inventory at each dealer $(\lambda=0.1)$. The second column shows the average inventory reduction that takes place at the dealers for each model. Column 3 presents the results for the average potential sales improvement for each car model. We find that exchanging inventory among dealers within a CBSA while give the dealers the option to reduce their inventory results in a reduction on average of 2.8 percent of the dealer's inventory and weighted average sales gain of 5.2 percent.

\subsection{State-wide Reallocation of Vehicles}

Instead of swapping vehicles after they arrive at dealerships, we now consider changing the allocation of vehicles after they leave the production facility. At that point in time there may be some flexibility with respect to a vehicle's final destination and this flexibility may come with little incremental cost. In particular, we estimate the sales gain that can be achieved through smarter allocation of vehicles that arrive to a particular state in a given week. With this approach there are no transfers among dealers - each dealer's initial inventory remains with that dealer. However, rather than send sub-model $k$ to a dealer who already has some units of sub-model $k$, it is better to send that vehicle to a dealer who begins the week without any units of sub-model $k$. Let $Y_{i j k}>0$ denote the number of incoming vehicles of model $j /$ sub-model $k$ that are allocated to dealer $i$. The resulting math program is similar to (4)-(8) but replacing constraints (5)-(6) by:

$$
\begin{gathered}
\sum_{i}^{n} Y_{i j k}=A_{j k} \\
\sum_{k}^{m_{j}} Q_{i j k} \leq M_{i j} \\
Q_{i j k}=I_{i j k}+Y_{i j k}
\end{gathered}
$$

Constraint (9) ensures that the state receives the same number of vehicles of model $j$ and submodel $k$ as we observed in our data for the chosen week. Constraint (10) ensures that dealer $i$ 's inventory of model $j$ after the assignment is not greater than the maximum number of vehicles of model $j$ that dealer $i$ had in any week of our sample. This precludes allocations that result in some dealers having an unreasonable large amount of inventory. Equation (11) states that the 
resulting dealer's inventory of a model equals the dealer's initial endowment, $I_{i j k}$, plus the dealer's allocation, $Y_{i j k}$.

The third column on Table 12 shows the results for each model in this state-wide allocation problem. On average, we find that routing vehicles to dealers in a state so as to minimize overlap within a dealer's inventory while maximizing variety across dealers yields an average sales increase of 2.8 percent.

\section{Conclusion}

We developed an econometric model to estimate the effect of inventory and variety on sales at U.S. automobile dealerships. There exists contradictory theory with respect to the impact of inventory on sales. There are several mechanisms that lead to a billboard effect - a positive relationship between inventory and sales. For example, at a basic level, adding inventory can increase sales by reducing stockouts, or by expanding the variety of sub-models available. However, there are mechanisms that lead to a scarcity effect - a negative relationship between inventory and sales. For instance, adding inventory may encourage additional search. In our sample, given how vehicles were allocated to dealerships, we find that an increase in inventory at a dealer actually lowers sales. Furthermore we decompose this effect into two parts: (1) increasing inventory of a sub-model does indeed reduce sales, but (2) if increasing inventory expands the number of sub-models available to customers, then sales increase. In short, the benefit of expanding variety can dominate the negative effect of increasing inventory within a sub-model. This result emphasizes that the total level of inventory can be a poor proxy for the presence of either a billboard or scarcity effect.

Our finding is consistent with two mechanisms relating inventory to sales: (i) expanded variety enables a better fit to consumer preferences, thereby increasing sales, and (ii) too many of the same sub-model encourages consumers to procrastinate their purchase decision, thereby lowering sales. To maximize sales a dealer wants to have one unit of each sub-model (to generate an urgency to "buy now before they are all gone") while also having as many sub-models available as possible, to cater to the heterogeneous tastes of consumers.

Our results emphasizes the importance of careful vehicle allocation. The data suggest that vehicles are allocated in a way that does not maximize the heterogeneity of sub-models available to consumers. Dealers may view one sub-model as particularly desirable and then take actions to increase their inventory in that sub-model rather than to expand the set of sub-models offered. For example, based on our estimates, an allocation policy that is focused on maximizing variety can increase sales by about 5.6 percent, without changing the number of vehicles produced or the number of vehicles each dealer carries. In other words, a sales increase is possible with essentially no additional cost. 


\section{References}

Albuquerque, Paulo, Bart J. Bronnenberg. 2012. Measuring the impact of negative demand shocks on car dealer networks. Marketing Science 31(1) 4-23.

AutomotiveNews. 2010. Dealers: We want more cars! in quest for profits, factories keep inventory tight. $\quad h t t p: / / w w w . a u t o n e w s . c o m / a p p s / p b c s . d l l / a r t i c l e ? A I D=/ 20100823 / O E M 01 / 308239949 / 1262$ David Barkholz.

Aviv, Yossi, Amit Pazgal. 2008. Optimal pricing of seasonal products in the presence of forward-looking consumers. Manufacturing \& Service Operations Management 10(3) 339-359.

Balachander, Subramanian, Yan Liu, Axel Stock. 2009. An empirical analysis of scarcity strategies in the automobile industry. Management Science 55(10) 1623-1637.

Balakrishnan, Anantaram, Michael S. Pangburn, Euthemia Stavrulaki. 2004. "stack them high, let 'em fly": Lot-sizing policies when inventories stimulate demand. Management Science 50(5) 630-644.

Bekker, Paul A. 1994. Alternative approximations to the distributions of instrumental variable estimators. Econometrica 62(3) pp. 657-681.

Bernstein, Fernando, Awi Federgruen. 2004. A general equilibrium model for industries with price and service competition. Operations Research 52(6) pp. 868-886.

Brehm, Sahron S., Jack W. Brehm. 1981. Psychological Reactance: A Theory of Freedom and Control. Academic Press, New York.

Brock, T. C. 1968. Implications of commodity theory for value change. New York: Academic Press.

Buse, A. 1992. The bias of instrumental variable estimators. Econometrica 60(1) pp. 173-180.

Busse, Meghan R, Devin G Pope, Jaren C Pope, Jorge Silva-Risso. 2014. The psychological effect of weather on car purchases. The Quarterly Journal of Economics qju033.

Cachon, Gérard P, Robert Swinney. 2009. Purchasing, pricing, and quick response in the presence of strategic consumers. Management Science 55(3) 497-511.

Cachon, Grard P., Christian Terwiesch, Yi Xu. 2008. On the effects of consumer search and firm entry in a multiproduct competitive market. Marketing Science 27(3) 461-473.

Chao, John C., Norman R. Swanson. 2005. Consistent estimation with a large number of weak instruments. Econometrica 73(5) pp. 1673-1692.

Dana Jr., James D., Nicholas C. Petruzzi. 2001. Note: The newsvendor model with endogenous demand. Management Science 47(11) 1488-1497.

DeGraba, Patrick. 1995. Buying frenzies and seller-induced excess demand. The RAND Journal of Economics 26(2) $331-342$.

Deneckere, Raymond, James Peck. 1995. Competition over price and service rate when demand is stochastic: A strategic analysis. The RAND Journal of Economics 26(1) pp. 148-162. 
Donald, Stephen G., Whitney K. Newey. 2001. Choosing the number of instruments. Econometrica 69(5) pp. 1161-1191.

Gourville, John T, Dilip Soman. 2005. Overchoice and assortment type: When and why variety backfires. Marketing science 24(3) 382-395.

Hoch, Stephen J., Eric T. Bradlow, Brian Wansink. 1999. The variety of an assortment. Marketing Science 18(4) pp. 527-546.

Iyengar, Sheena S., Mark R. Lepper. 2000. When choice is demotivating: Can one desire too much of a good thing? Journal of Personality \& Social Psychology 79 995-1006.

Kalyanam, Kirthi, Sharad Borle, Peter Boatwright. 2007. Deconstructing each item's category contribution. Marketing Science 26(3) 327-341.

Kloek, T., L. B. M. Mennes. 1960. Simultaneous equations estimation based on principal components of predetermined variables. Econometrica 28(1) pp. 45-61.

Kuksov, Dmitri, J. Miguel Villas-Boas. 2010. When more alternatives lead to less choice. Marketing Science 29(3) 507-524.

Matsa, David A. 2011. Competition and product quality in the supermarket industry. The Quarterly Journal of Economics 126(3) pp. 1539-1591.

Moreno, Antonio, Christian Terwiesch. 2015. Pricing and production flexibility: An empirical analysis of the u.s. automotive industry. Manufacturing $\mathcal{E}$ Service Operations Management 17(4) 428-444.

Murray, Kyle B., Fabrizio Di Muro, Adam Finn, Peter Popkowski Leszczyc. 2010. The effect of weather on consumer spending. Journal of Retailing and Consumer Services 17(6) 512 - 520.

NOAA. 2015. Storm data publication. http://www.ncdc.noaa.gov/stormevents/ftp.jsp.

NOAA. 2016. National weather service instruction. http://www.nws.noaa.gov/directives/sym/pd01016005curr.pdf.

Qian, Liu, Garrett J. van Ryzin. 2008. Strategic capacity rationing to induce early purchases. Management Science 54(6) 1115-1131.

Schwartz, Barry. 2004. The Paradox of Choice: Why More Is Less. Ecco/HarperCollins Publishers.

Smith, Stephen A., Dale D. Achabal. 1998. Clearance pricing and inventory policies for retail chains. Management Science 44(3) 285-300.

Soysal, Gonca P., Lakshman Krishnamurthi. 2012. Demand dynamics in the seasonal goods industry: an empirical analysis. Marketing Science 31(2) 293-316.

Steele, A. T. 1951. Weather's effect on the sales of a department store. Journal of Marketing 15(4) pp. 436-443.

Stock, Axel, Subramanian Balachander. 2005. The making of a "hot product": A signaling explanation of marketers' scarcity strategy. Management Science 51(8) 1181-1192. 
Su, Xuanming, Fuqiang Zhang. 2008. Strategic customer behavior, commitment, and supply chain performance. Management Science 54(10) 1759-1773.

$\mathrm{Su}$, Xuanming, Fuqiang Zhang. 2009. On the value of commitment and availability guarantees when selling to strategic consumers. Management Science 55(5) pp. 713-726.

Talluri, Kalyan, Garrett van Ryzin. 2004. Revenue management under a general discrete choice model of consumer behavior. Management Science 50(1) pp. 15-33.

Tereyağoğlu, Necati, Senthil Veeraraghavan. 2012. Selling to conspicuous consumers: Pricing, production, and sourcing decisions. Management Science 58(12) 2168-2189.

Train, Kenneth E. 2009. Discrete Choice Methods with Simulation. 2nd ed. Cambridge University Press.

Worchel, Stephen, Jerry Lee, Akanbi Adewole. 1975. Effects of supply and demand on ratings of object value. Journal of Personality and Social Psychology 32(5) 906 - 914.

Zettelmeyer, Florian, Fiona Scott Morton, Jorge Silva-Risso. 2006. Scarcity rents in car retailing: Evidence from inventory fluctuations at dealerships. NBER . 


\section{Appendix: Tables and Figures}

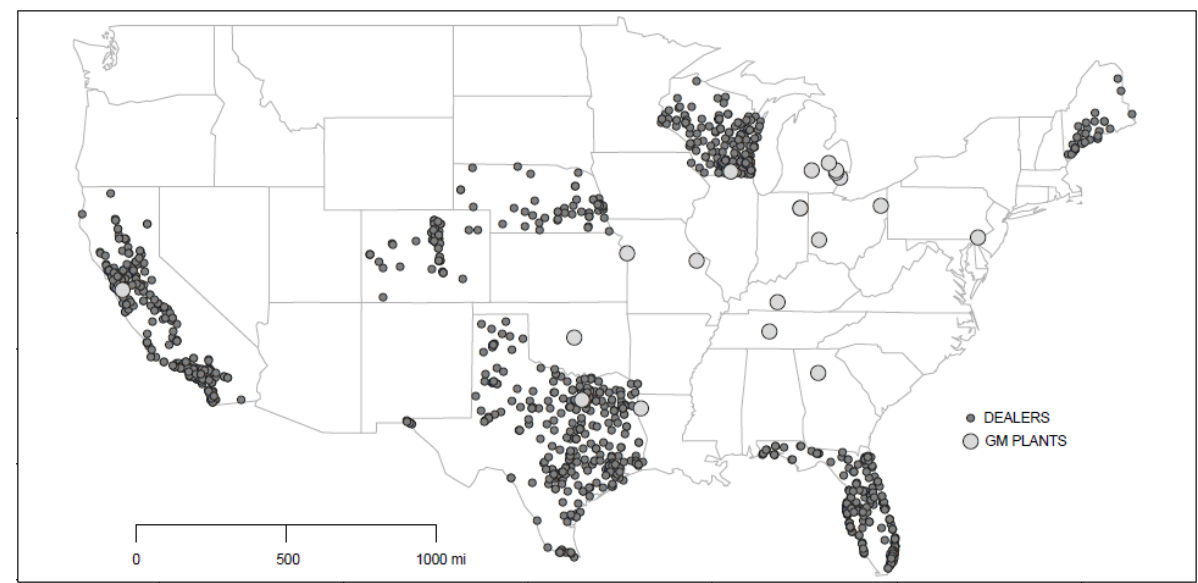

Figure 1 Dealer and Plant Locations in Our Sample

Table 1 Dealers by State

\begin{tabular}{lr}
\hline \hline State & Number of Dealers \\
\hline California & 355 \\
Colorado & 67 \\
Florida & 237 \\
Maine & 31 \\
Nebraska & 50 \\
Texas & 366 \\
Wisconsin & 183 \\
\hline Total & 1,289 \\
\hline \hline
\end{tabular}

Table 2 Weather Variables Included in the Study

\begin{tabular}{|c|c|c|c|c|c|c|}
\hline Variable & Description & Avg & $\mathrm{Sd}$ & Median & Min & Max \\
\hline Wind & $\begin{array}{l}\text { Number of days in which a wind advisory is issued } \\
\text { by the National Weather Service Forecast Office. }\end{array}$ & 0.01 & 0.11 & 0.00 & 0.00 & 1.00 \\
\hline Cloud & $\begin{array}{l}\text { Average cloud cover during the week } \\
(0=\text { no clouds; } 8=\text { sky completely covered })\end{array}$ & 3.83 & 1.98 & 3.71 & 0.00 & 7.85 \\
\hline Fog 1 & Weeks with 1 days with fog during the week. & 0.15 & 0.36 & 0.00 & 0.00 & 1.00 \\
\hline Fog 2-3 & Weeks with 2 or 3 days of fog during the week. & 0.09 & 0.29 & 0.00 & 0.00 & 1.00 \\
\hline Fog 4-7 & Weeks with more than 3 days of fog during the week. & 0.02 & 0.13 & 0.00 & 0.00 & 1.00 \\
\hline Rain 1-2 & Weeks with 1 or 2 days of rain during the week. & 0.37 & 0.48 & 0.00 & 0.00 & 1.00 \\
\hline Rain 3-5 & Weeks with 3 to 5 days of rain during the week. & 0.33 & 0.47 & 0.00 & 0.00 & 1.00 \\
\hline Rain 6-7 & Weeks with more than 5 days of rain during the week. & 0.01 & 0.09 & 0.00 & 0.00 & 1.00 \\
\hline Snow 1 & Weeks with 1 day of snow during the week. & 0.12 & 0.32 & 0.00 & 0.00 & 1.00 \\
\hline Snow 2-4 & Weeks with 2 to 4 days of rain during the week. & 0.11 & 0.31 & 0.00 & 0.00 & 1.00 \\
\hline Snow 5-7 & Weeks with more than 4 days of rain during the week. & 0.03 & 0.16 & 0.00 & 0.00 & 1.00 \\
\hline High Temp 1 & $\begin{array}{l}\text { Weeks with } 1 \text { day of high temperature, } \\
\text { above } 90 \text { degrees Fahrenheit, during the week. }\end{array}$ & 0.12 & 0.32 & 0.00 & 0.00 & 1.00 \\
\hline High Temp 2-5 & $\begin{array}{l}\text { Weeks with } 2 \text { to } 5 \text { days of high temperature, } \\
\text { above } 90 \text { degrees Fahrenheit, during the week. }\end{array}$ & 0.07 & 0.25 & 0.00 & 0.00 & 1.00 \\
\hline High Temp 6-7 & $\begin{array}{l}\text { Weeks with more than } 5 \text { days of high temperature, } \\
\text { above } 90 \text { degrees Fahrenheit, during the week. }\end{array}$ & 0.02 & 0.13 & 0.00 & 0.00 & 1.00 \\
\hline
\end{tabular}


Table 3 Model Variety for the Top Ten Selling Models

\begin{tabular}{lcc}
\hline \hline & $\begin{array}{c}\text { Total Model Variety } \\
(\text { MarketVar })\end{array}$ & $\begin{array}{c}\text { Average Variety Available } \\
(\text { AvailVar })\end{array}$ \\
\hline Cobalt & 18 & 3.5 \\
Equinox & 4 & 2.2 \\
G6 & 37 & 6.1 \\
HHR & 4 & 2.9 \\
Impala & 10 & 3.7 \\
Suburban & 18 & 4.5 \\
Tahoe & 13 & 4.0 \\
TrailBlazer & 10 & 2.1 \\
Saturn VUE & 5 & 4.6 \\
Yukon & 30 & 8.6 \\
\hline \hline Average & 14.9 & 4.2 \\
\hline
\end{tabular}

Market Var is the maximum number of variants that could be produced for the model.

AvailVar is the number of variants with at least one unit during a particular week.

Table 4 Descriptive Statistics

\begin{tabular}{|c|c|c|c|c|}
\hline Variable & Mean & $\begin{array}{l}\text { Standard } \\
\text { Deviation }\end{array}$ & Min. & Max. \\
\hline Sales (units) & 0.75 & 1.47 & 0 & 35 \\
\hline Inventory (units) & 11.67 & 14.83 & 0 & 193 \\
\hline Variety (count) & 3.14 & 2.664 & 0 & 21 \\
\hline Variety Percentage (\%) & 36.76 & 27.35 & 0 & 100 \\
\hline
\end{tabular}

Total Number of Observations 216,438

Table 5 Correlation Table

\begin{tabular}{lcccc}
\hline \hline & Sales & Inventory & Variety & $\begin{array}{c}\text { Variety } \\
\text { Percentage }\end{array}$ \\
\hline Sales & & & & \\
Inventory & 0.00 & 1.00 & & \\
Variety & 0.39 & 0.70 & 1.00 & \\
Variety Percentage & 0.23 & 0.31 & 0.12 & 1.00 \\
\hline \multicolumn{5}{r}{ Total Number of Observations 216,438 }
\end{tabular}




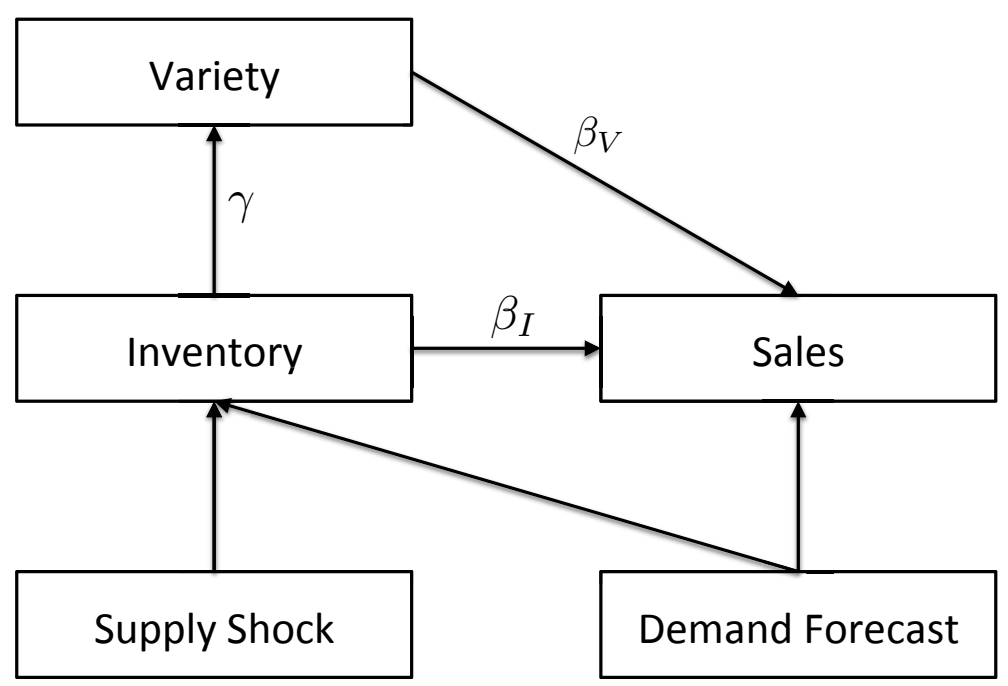

Figure 2 Relationship between Sales, Inventory and Variety

Table 6 First Stage Inventory Analysis - Weather Factors

\begin{tabular}{lll}
\hline \hline & Inventory & Variety \\
\hline Thunder & $1.309^{* * *}$ & $0.008^{* * *}$ \\
Heat & $(0.088)$ & $(0.002)$ \\
& $0.346^{*}$ & $-0.007^{*}$ \\
Wind & $(0.164)$ & $(0.003)$ \\
& $-1.210^{* * *}$ & $0.018^{* * *}$ \\
Winter & $(0.112)$ & $(0.002)$ \\
& $-0.737^{* * *}$ & -0.001 \\
Flood & $(0.057)$ & $(0.001)$ \\
& $1.679^{* * *}$ & $0.004^{*}$ \\
Tropical & $(0.101)$ & $(0.002)$ \\
& $0.910^{* *}$ & $-0.114^{* * *}$ \\
VarietyD1 & $(0.324)$ & $(0.006)$ \\
& $3.974^{* * *}$ & $0.055^{* * *}$ \\
VarietyD2 & $(0.121)$ & $(0.002)$ \\
& $3.671^{* * *}$ & $0.049^{* * *}$ \\
VarietyD3 & $(0.118)$ & $(0.002)$ \\
& $3.037^{* * *}$ & $0.054^{* * *}$ \\
\hline Dealer-Model Fixed Effects & $(0.111)$ & $(0.002)$ \\
Dummies for Each Week and Region & YES & YES \\
Dealer's Local Weather & YES & YES \\
\hline Observations & 216,438 & 216,438 \\
Dealer-Models & 9,663 & 9,663 \\
\hline \hline
\end{tabular}

Robust Standard errors in parentheses

${ }^{*} p<0.05,{ }^{* *} p<0.01,{ }^{* * *} p<0.001$ 
Table 7 Main Model Results

\begin{tabular}{lccccc}
\hline \hline & $(1)$ & $(2)$ & $(3)$ & $(4)$ & $(5)$ \\
\hline Inventory & $0.0115^{* * *}$ & $-0.008^{* * *}$ & $-0.008^{* * *}$ & $0.013^{* * *}$ & $-0.009^{* *}$ \\
& $(0.000)$ & $(0.002)$ & $(0.002)$ & $(0.000)$ & $(0.003)$ \\
Variety & $0.308^{* * *}$ & $0.478^{* * *}$ & $0.621^{* * *}$ & & \\
& $(0.011)$ & $(0.118)$ & $(0.047)$ & & \\
\hline Dealer-Model Fixed Effects & YES & YES & YES & YES & YES \\
Dummies for Each Week and Region & YES & YES & YES & YES & YES \\
Dealer's Local Weather & YES & YES & YES & YES & YES \\
\hline Observations & 216,438 & 216,438 & 216,438 & 216,438 & 216,438 \\
Dealer-Models & 9,663 & 9,663 & 9,663 & 9,663 & 9,663 \\
\hline \hline
\end{tabular}

Robust Standard errors in parentheses

${ }^{*} p<0.05,{ }^{* *} p<0.01,{ }^{* * *} p<0.001$

(1) Estimation results for the impact of inventory and variety without instrumenting inventory or variety.

(2) Estimation results for the impact of inventory and variety instrumenting the endogenous inventory and variety.

(3) Estimation results for the impact of inventory and variety instrumenting only the endogenous inventory.

(4) Estimation results obtained without instrumenting inventory.

(5) Estimation results obtained instrumenting inventory.

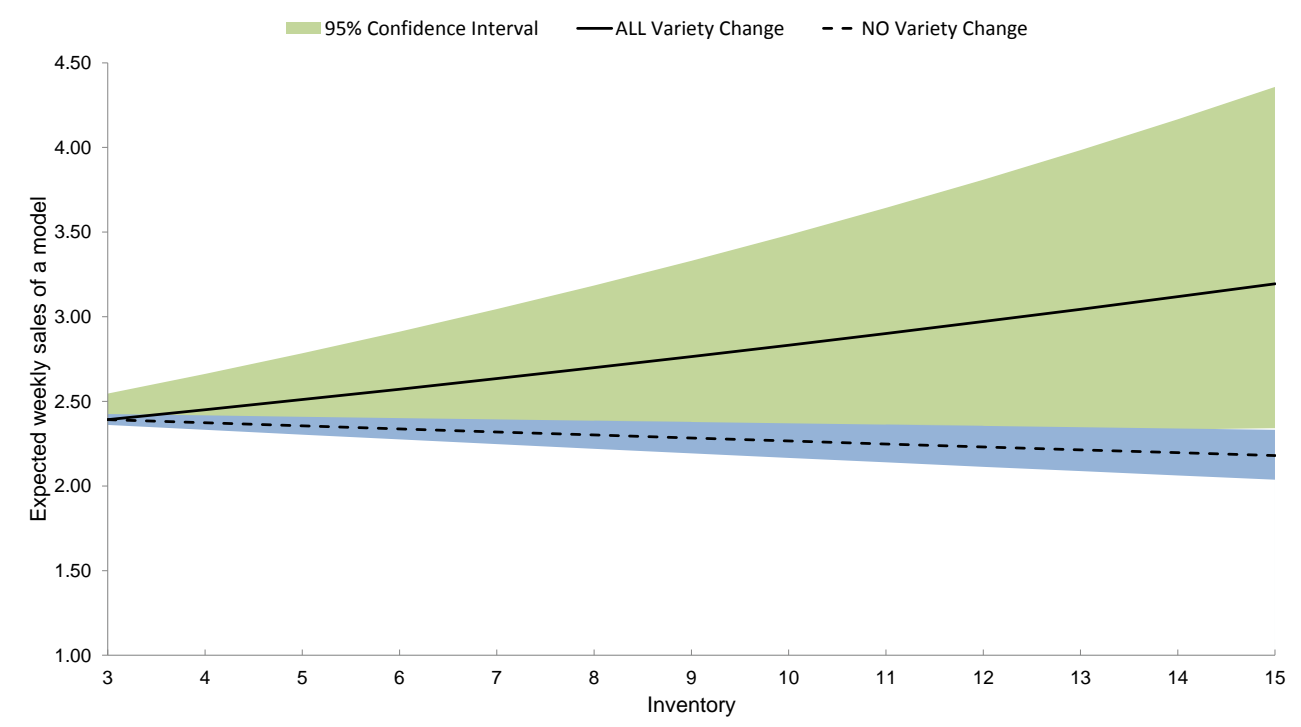

The Figure illustrates the overall impact of inventory on sales with the vehicle allocation policy that maximizes the expansion of variety (black line) compared to the allocation policy that expands inventory without increasing the number of sub-models available (dashed line), for a dealer that starts with 3 vehicles of a particular model.

Figure 3 Sensitivity Analysis 
Table $8 \quad$ Alternative Seasonal Controls

\begin{tabular}{lcccccc}
\hline \hline & $(1)$ & $(2)$ & $(3)$ & $(4)$ & $(5)$ & $(6)$ \\
\hline Inventory & $-0.008^{* * *}$ & $-0.007^{* *}$ & $-0.007^{* *}$ & $-0.014^{* * *}$ & $-0.014^{* *}$ & $-0.028^{* * *}$ \\
& $(0.002)$ & $(0.002)$ & $(0.002)$ & $(0.004)$ & $(0.004)$ & $(0.005)$ \\
Variety & $0.478^{* *}$ & $0.466^{* *}$ & $0.466^{* *}$ & $1.207^{*}$ & $1.207^{*}$ & $1.610^{* *}$ \\
& $(0.158)$ & $(0.160)$ & $(0.160)$ & $(0.555)$ & $(0.555)$ & $(0.565)$ \\
\hline Dealer-Model Fixed Effects & YES & YES & YES & YES & YES & YES \\
Seasonal Control & $\mathrm{A}$ & $\mathrm{B}$ & $\mathrm{C}$ & $\mathrm{D}$ & $\mathrm{E}$ & $\mathrm{F}$ \\
Dealer's Local Weather & YES & YES & YES & YES & YES & YES \\
\hline Observations & 216,438 & 216,438 & 216,438 & 216,438 & 216,438 & 216,438 \\
Dealer-Models & 9,663 & 9,663 & 9,663 & 9,663 & 9,663 & 9,663 \\
\hline \hline
\end{tabular}

Robust Standard errors in parentheses

${ }^{*} p<0.05,{ }^{* *} p<0.01,{ }^{* * *} p<0.001$

(A) Base Model. Weekly dummies interacted with 4 different zones. (104 dummies Total)

(B) Individual weekly dummies and a dummy for each one of the zones. (30 dummies Total)

(C) Weekly dummies interacted with 26 different vehicle models. (676 dummies Total)

(D) Individual weekly dummies and a dummy for each one of the modes. (52 dummies Total)

(E) Individual trend for each one of the 26 vehicle models.(26 separate trends by model)

(F) Weekly dummies and Individual model trend.(26 dummies Total and 26 separate trends)

Table $9 \quad$ Alternative Weather Instruments and Additional Plants

\begin{tabular}{lcccc}
\hline \hline & $(1)$ & $(2)$ & $(3)$ & $(4)$ \\
\hline Inventory & $-0.013^{* *}$ & $-0.015^{* * *}$ & $-0.012^{* *}$ & $-0.018^{* * *}$ \\
Variety & $(0.004)$ & $(0.003)$ & $(0.004)$ & $(0.003)$ \\
& $0.764^{* *}$ & & $0.764^{* *}$ & \\
& $(0.304)$ & & $(0.269)$ & \\
\hline Dealer-Model Fixed Effects & YES & YES & YES & YES \\
Dummies for Each Week and Region & YES & YES & YES & YES \\
Dealer's Local Weather & YES & YES & YES & YES \\
\hline Observations & 216,438 & 216,438 & 290,906 & 290,906 \\
Dealer-Models & 9,663 & 9,663 & 12,853 & 12,853 \\
\hline \hline
\end{tabular}

Robust Standard errors in parentheses

${ }^{*} p<0.05,{ }^{* *} p<0.01,{ }^{* * *} p<0.001$

(1) Estimation results for the impact of inventory and variety instrumenting inventory with weather factors.

(2) Estimation results for the impact of inventory instrumenting inventory with weather factors.

(3) Estimation results for the impact of inventory and variety instrumenting inventory and variety with weather factors. Including additional Plants.

(4) Estimation results for the impact of inventory instrumenting inventory with weather factors. Including additional Plants. 
Table $10 \quad$ Isolated Dealers Analysis

\begin{tabular}{lcccc}
\hline \hline & $(1)$ & $(2)$ & $(3)$ & $(4)$ \\
\hline Inventory & $0.010^{* * *}$ & $-0.016^{* * *}$ & $0.012^{* * *}$ & $-0.020^{* *}$ \\
& $(0.000)$ & $(0.004)$ & $(0.000)$ & $(0.006)$ \\
Variety & $0.295^{* *}$ & $0.784^{* *}$ & & \\
& $(0.015)$ & $(0.290)$ & & \\
\hline Dealer-Model Fixed Effects & YES & YES & YES & YES \\
Dummies for Each Week and Region & YES & YES & YES & YES \\
Dealer's Local Weather & YES & YES & YES & YES \\
\hline Observations & 112,177 & 112,177 & 112,177 & 112,177 \\
Dealer-Models & 5,131 & 5,131 & 5,131 & 5,131 \\
\hline \hline
\end{tabular}

Robust Standard errors in parentheses

${ }^{*} p<0.05,{ }^{* *} p<0.01,{ }^{* * *} p<0.001$

(1) Estimation results for the impact of inventory and variety without instrumenting inventory or variety.

(2) Estimation results for the impact of inventory and variety instrumenting the endogenous inventory and variety.

(3) Estimation results obtained without instrumenting inventory.

(4) Estimation results obtained instrumenting inventory.

Table 11 Transfers Robustness

\begin{tabular}{lcc}
\hline \hline & $(1)$ & $(2)$ \\
\hline Inventory & $-0.008^{* * *}$ & $-0.008^{* * *}$ \\
Variety & $(0.002)$ & $(0.002)$ \\
& $0.478^{* *}$ & $0.468^{* *}$ \\
& $(0.158)$ & $(0.166)$ \\
\hline Dealer-Model Fixed Effects & YES & YES \\
Dummies for Each Week and Region & YES & YES \\
Dealer's Local Weather & YES & YES \\
\hline Observations & 216,438 & 216,438 \\
Dealer-Models & 9,663 & 9,663 \\
\hline \hline
\end{tabular}

Robust Standard errors in parentheses

${ }^{*} p<0.05,{ }^{* *} p<0.01,{ }^{* * *} p<0.001$

(1) Base Case. Dealers outside a 150 mile radius for the variety instrument.

(2) Dealers outside a 200 mile radius for the variety instrument.

Table 12 The Impact of Inventory Allocation

\begin{tabular}{|c|c|c|c|c|}
\hline & \multicolumn{3}{|c|}{ CBSA Reallocation } & \multirow{3}{*}{$\begin{array}{c}\text { State } \\
\text { Reallocation } \\
\text { Sales increase }(\%)\end{array}$} \\
\hline & \multirow{2}{*}{$\begin{array}{c}\text { No Inventory } \\
\text { Reduction Allowed } \\
\text { Sales Increase (\%) }\end{array}$} & \multicolumn{2}{|c|}{$\begin{array}{c}10 \% \text { Inventory } \\
\text { Reduction Allowed }\end{array}$} & \\
\hline & & Inventory Reduction (\%) & Sales Increase(\%) & \\
\hline Cobalt & 4.2 & 1.2 & 4.5 & 2.9 \\
\hline Equinox & 4.6 & 2.4 & 5.0 & 2.2 \\
\hline G6 & 5.0 & 1.8 & 5.3 & 2.3 \\
\hline HHR & 5.1 & 4.7 & 5.8 & 6.8 \\
\hline Impala & 5.9 & 2.0 & 6.4 & 5.1 \\
\hline Suburban & 4.6 & 1.4 & 4.9 & 1.8 \\
\hline Tahoe & 3.9 & 2.5 & 4.6 & 1.9 \\
\hline TrailBlazer & 4.8 & 1.2 & 5.3 & 1.0 \\
\hline Saturn VUE & 1.1 & 9.1 & 5.0 & 2.2 \\
\hline Yukon & 3.9 & 3.8 & 5.1 & 2.5 \\
\hline Weighted Average & 4.4 & 2.8 & 5.2 & 2.8 \\
\hline
\end{tabular}

